\title{
Mitral valve perforation after left lateral accessory pathway ablation: a case report
}

\author{
Mariem Jabeur ${ }^{1} \mathbb{0}$, Adrien Carabelli ${ }^{1}$, Peggy Jacon${ }^{1}$, Sandrine Venier ${ }^{1}$, Jean-François Obadia² and \\ Pascal Defaye ${ }^{1 *}$
}

\begin{abstract}
Background: Radiofrequency catheter ablation is considered to be a relatively safe procedure. This is an unusual case report in which severe mitral regurgitation was occurred after left lateral accessory pathway radiofrequency catheter ablation.

Case presentation: A 15-year-old man without structural heart disease was referred for ablation of a left lateral accessory pathway. He was a rugby player who had lived with Wolff-Parkinson-White syndrome since 2017. In 2017, two failed extensive radiofrequency catheter ablations of a left lateral accessory pathway had been performed in another center. In June 2018, he underwent a third radiofrequency catheter ablation of a left lateral accessory pathway using an anterograde transseptal approach with an early recurrence one month later. A successful fourth procedure was performed in August 2018 using a retrograde aortic approach. Three months later, the patient presented to the hospital with atypical chest pain and dyspnea on exertion. Transthoracic echocardiography revealed severe mitral regurgitation caused by a perforation of the posterior leaflet. Given the symptoms and the severity of the mitral valve regurgitation, the decision was taken to proceed with surgical intervention. Posterior mitral leaflet perforation was confirmed intraoperatively. The patient underwent video-assisted mitral valve repair via Minithoracotomy approach.
\end{abstract}

Conclusion: This case demonstrates a very rare complication of Wolff-Parkinson-White radiofrequency ablation.

Keywords: Left lateral accessory pathway, Catheter ablation, Mitral valve perforation, Mitral valve repair,

Minithoracotomy

\section{Background}

Radiofrequency catheter ablation is an effective treatment of accessory pathway. It is considered to be a relatively safe procedure. This is an unusual case report in which severe mitral regurgitation was occurred after left lateral accessory pathway ablation.

\section{Case presentation}

In August 2018, a 15-year-old athletic male with symptomatic Wolff-Parkinson-White syndrome underwent a fourth electrophysiological study and subsequent ablation for orthodromic reentrant tachycardia using a left lateral accessory pathway.

Two failed extensive radiofrequency catheter ablations of a left lateral accessory pathway had been performed in 2017 in another center. A three-dimensional mapping system was already used during the second procedure.

In April 2018, a third catheter ablation procedure using an anterograde transseptal approach was performed in our center with an early recurrence one month later.

A fourth ablation procedure was performed with 7French medium-curl Biosense catheter using the original author(s) and the source, provide a link to the Creative Commons licence, and indicate if changes were made. The images or other third party material in this article are included in the article's Creative Commons licence, unless indicated otherwise in a credit line to the material. If material is not included in the article's Creative Commons licence and your intended use is not permitted by statutory regulation or exceeds the permitted use, you will need to obtain permission directly from the copyright holder. To view a copy of this licence, visit http://creativecommons.org/licenses/by/4.0/. The Creative Commons Public Domain Dedication waiver (http://creativeco mmons.org/publicdomain/zero/1.0/) applies to the data made available in this article, unless otherwise stated in a credit line to the data. 


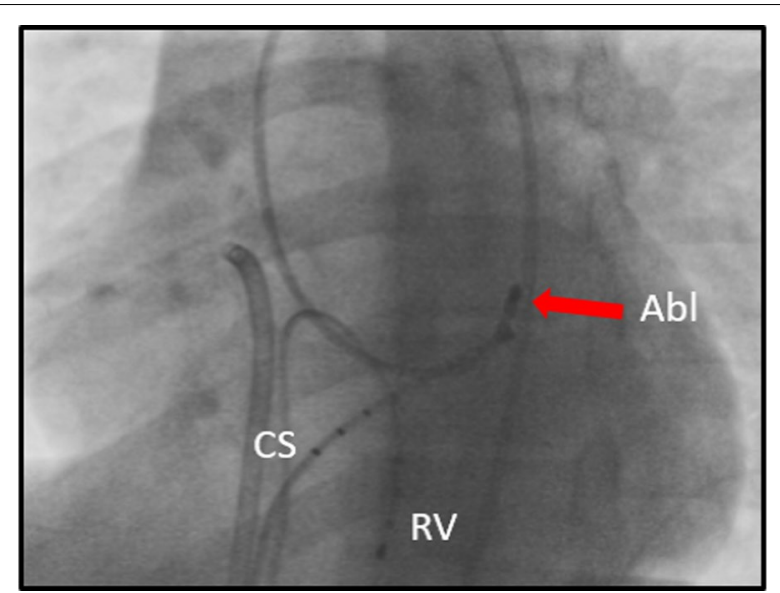

Fig. 1 Catheter ablation position (left anterior oblique view) retrograde aortic approach (Fig. 1). Thirty-two radiofrequency lesions were delivered at the mitral valve annulus $\left(50 \mathrm{~W}, 65^{\circ} \mathrm{C}\right)$.

Three months later, the patient presented to the hospital with atypical chest pain and dyspnea on exertion. Transthoracic echocardiography revealed severe mitral regurgitation with a regurgitant volume of $65 \mathrm{ml}$ and an estimated regurgitant orifice of $42 \mathrm{~mm}^{2}$ (Fig. 2a) caused by a perforation of the posterior leaflet. This perforation measured $5 \mathrm{~mm}$ (Fig. 2b). The left ventricular ejection fraction was $60 \%$.

Given the symptoms and the severity of the mitral valve regurgitation, the decision was taken to proceed with surgical intervention through Minithoracotomy approach. Upon opening of the left atrium and exposure

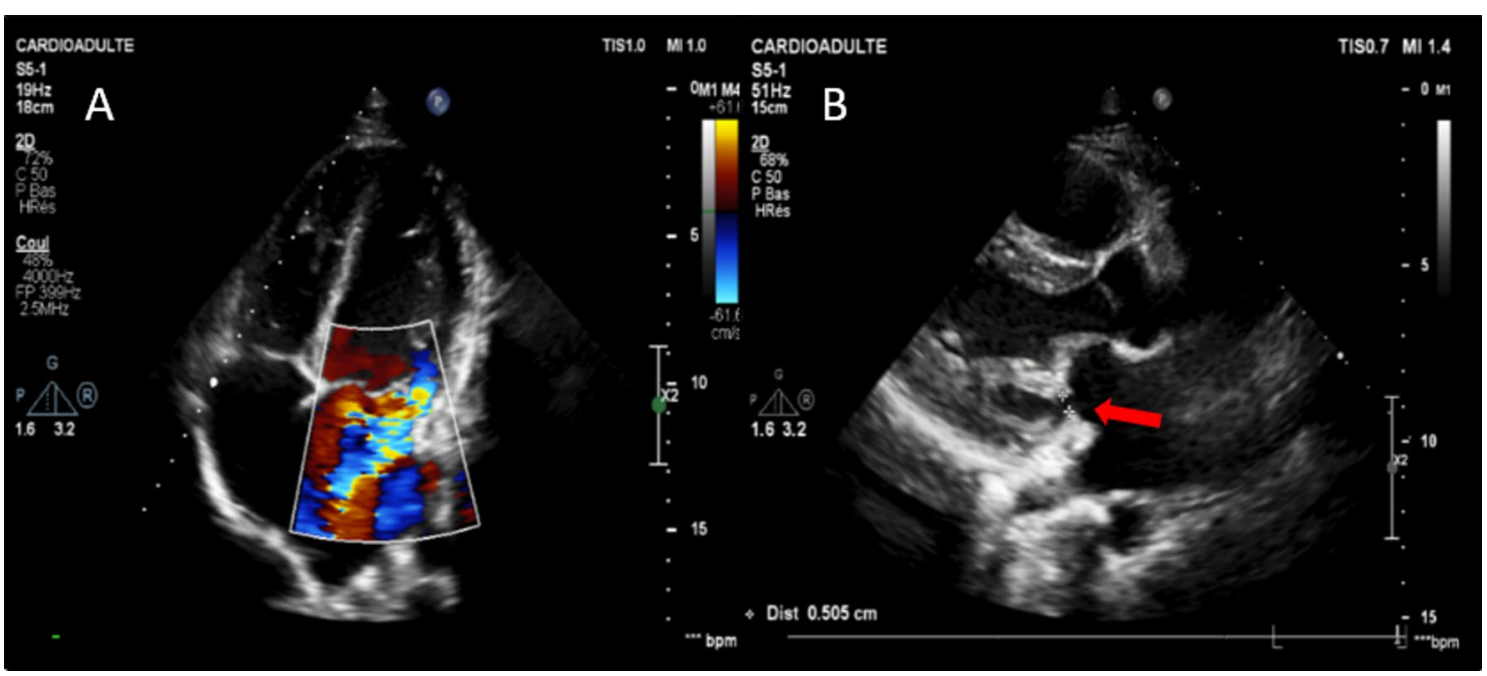

Fig. 2 Transthoracic echocardiogram demonstrating mitral valve regurgitation; a four cavities view showing the eccentric jet of mitral regurgitation; $\mathbf{b}$ parasternal long-axis view showing the perforation of mitral posterior leaflet

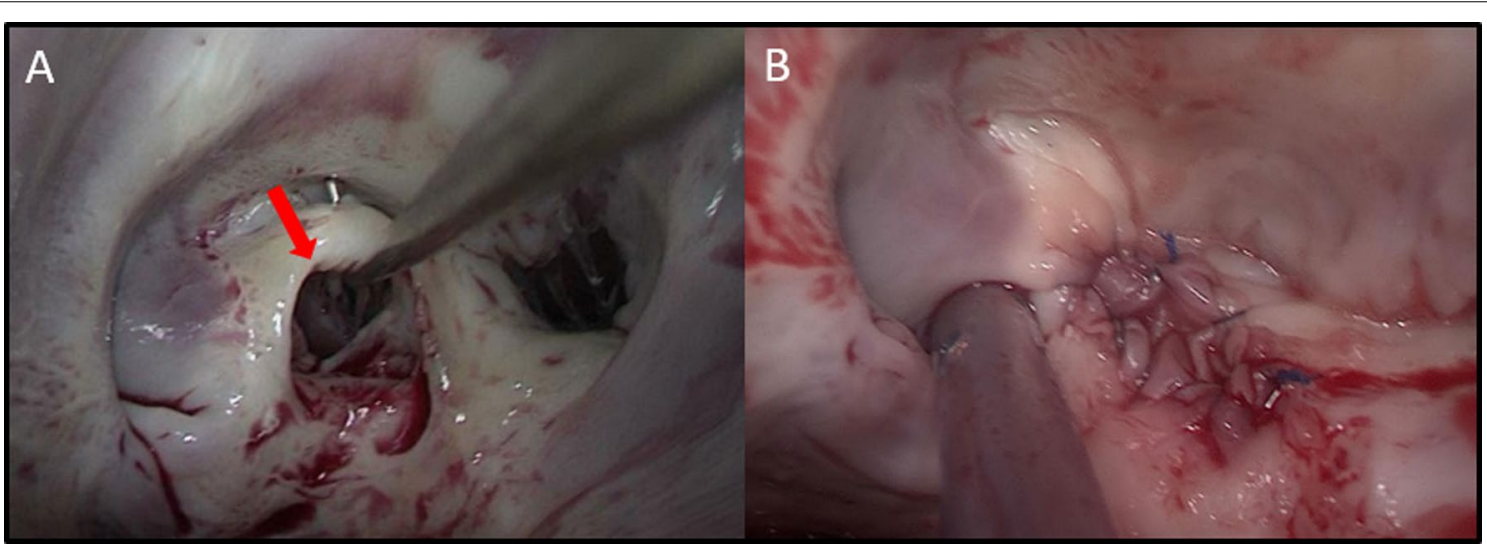

Fig. 3 Mitral valve intraoperative photograph. a A perforation of the posterior leaflet; b Mitral valve repair 
of the mitral valve, a perforation of the posterior leaflet corresponding to the medial (Fig. 3a) was confirmed. The quality of the tissue was good. The patient underwent video-assisted mitral valve repair with simple suture (Fig. 3b).

He was discharged from the hospital on postoperative day three. Postoperative transthoracic echocardiography showed mild mitral regurgitation and excellent biventricular function.

\section{Discussion}

Radiofrequency catheter ablation is an effective treatment for Wolff-Parkinson-White syndrome in children and adults. The incidence of major complications is between 3 and 4\% [1]. Compared to adults, children are at a higher risk for valvular, myocardial, and pericardial damage [2]. Ablation of the left-sided accessory pathway has the potential for injury to the mitral valve when a retrograde approach is used because the catheter is placed under the posterior leaflet of the mitral valve [1].

In one pediatric study, the incidence of mitral regurgitation after left side accessory pathway radiofrequency ablation was 9\% [3]. However, the incidence of severe mitral regurgitation caused by a perforation is unknown. There are only a few cases described in the literature.

The tissue lesions could have been caused by direct thermal injury or by catheter manipulation [1].The tissue lesions caused by the radiofrequency energy may directly injure the valvar structure. The lesions are placed at the base of the leaflets, and may cause valvar insufficiency if a leaflet or a chord is trapped underneath the tip of the catheter [3].

The perforation, in this case, was likely due to direct current injury from radiofrequency. All the more so, the patient had undergone prolonged procedures with a high number of energy applications, which may have contributed to the injury. The treatment for severe mitral regurgitation is surgical reparation. Medium-term Echocardiographic follow-up is not routinely practiced after radiofrequency ablation. However, it may be useful in detecting complications following high-risk procedures that involve a large number or long duration of ablations [2].

\section{Conclusion}

Tis case demonstrates the management of a very rare complication of Wolff-Parkinson-White radiofrequency ablation.

\section{Acknowledgements}

Not applicable.
Authors' contributions

The ablation was performed by PD and MJ. The echocardiography was performed by MJ. JFO did the surgery. All authors read and approved the final manuscript.

Funding

Not applicable.

Availability of data and materials

Not applicable.

\section{Declarations}

Ethics approval and consent to participate

Not applicable.

Consent for publication

Done.

Competing interests

The authors declare that they have no competing interests.

Author details

${ }^{1}$ Arrhythmias Unit, Department of Cardiology, Grenoble University Hospital, CS 10217, 38043 Grenoble Cedex 09, France. ${ }^{2}$ Department of Cardiovascular Surgery, Louis Pradel Hospital, 59 Boulevard Pinel, 69500 Bron, France.

Received: 5 November 2020 Accepted: 1 November 2021

Published online: 07 March 2022

References

1. Canal JGP, Enriquez-Sarano M, Asirvatham SJ, Munger TM, Friedman PA, Suri RM. Mitral valve injury after radiofrequency ablation for Wolff-Parkinson-white Syndrome. Circulation. 2013;127:2551-2.

2. Amdani SM, Sallaam S, Karpawich PP, Aggarwal S. Utility of echocardiography in detecting silent complications after pediatric catheter ablations. Pediatr Cardiol. 2017;38:1426-33.

3. Olsson A, Darpö B, Bergfeldt L, Rosenqvist M. Frequency and long term follow up of valvar insufficiency caused by retrograde aortic radiofrequency catheter ablation procedures. Heart. 1999;81:292-6.

\section{Publisher's Note}

Springer Nature remains neutral with regard to jurisdictional claims in published maps and institutional affiliations.

Ready to submit your research? Choose BMC and benefit from:

- fast, convenient online submission

- thorough peer review by experienced researchers in your field

- rapid publication on acceptance

- support for research data, including large and complex data types

- gold Open Access which fosters wider collaboration and increased citations

- maximum visibility for your research: over $100 \mathrm{M}$ website views per year

At BMC, research is always in progress.

Learn more biomedcentral.com/submissions 